\title{
Communication
}

\section{Enquête sérologique sur la prévalence de l'infection par l'herpès virus bovin type 4 dans les troupeaux bovins des plaines d'Accra au Ghana}

\author{
P. Marchot ${ }^{1}$ \\ E. Thiry ${ }^{2}$ \\ P. Jetteur ${ }^{2}$ \\ P. Leroy ${ }^{2}$
}

MARCHOT (P.), THIRY (E.), JETTEUR (P.), LEROY (P.). Enquête sérologique sur la prévalence de l'infection par l'hcrpc̀s virus bovin type 4 dans les troupeaux bovins des plaines d'Accra au Ghana. Revue Elev. Méd. vét. Pays trop., 1991, 44 (4) : 405-406

Les anticorps envers l'herpès virus bovin type 4 (BHV-1) ont été recherchés par un test d'immunofluorescence indirecte sur des sérums de bovins des plaines d'Accra au Ghana. Quatorze pour cent des 176 sérums examinés sont positifs à la dilution $1 / 100$. Des études complémentaires sont nécessaires pour mieux comprendre les relations existant entre le BHV-4 ou d'autres agents, et les vaginites nécrotiques et les problèmes de fertilité ohservés sur le hétail dans la région. Mots clés : Bovin - Enquête pathologique - Herpès virus bovin type 4 - Vaginite - Fertilité - Ghana.

Le groupe des virus herpès bovin type 4 (BHV-4) est constitué d'herpès-virus antigéniquement apparentés, largement répandus et peu ou pas pathogènes pour le gros bétail. Les souches virales sont isolées d'animaux en bonne santé ou atteints de troubles divers tels que: affections oculaires et respiratoires, maladies du système reproducteur, lésions cutanées, fièvre catarrhale et entérite (6).

Les plaines d'Accra au Ghana s'étendent de la Volta au Golfe de Guinée. L'élevage bovin est la principale activité de cette région où l'on observe la plus forte concentration d'animaux (62 000 têtes) pour le sud du pays. Une forte incidence (près de 20 p. 100) de vaginite nécrotique a été constatée dans certains troupeaux. Le BHV-4 était suspecté (5) et une enquête sérologique a été réalisée dans quelques troupeaux de la région.

Les sérums prélevés en 1988 au ranch d'Aveyime (principale station d'élevage) sur du bétail White Fulani, et dans quelques villages de la région sur du bétail West African Shorthorn ont été examinés par immunofluores-

1. FAO, Via delle Terme di Caracalla, 00100 Roma, Italie.

2. Service de Virologie-Immunologie et de BiostatistiqueInformatique, Faculté de Médecine vétérinaire, Université de Liège, B-1070 Bruxelles, Belgique.

Reçu le 19.6.1991, accepté le 19.9.1991.
TABLEAU I Prévalence des animaux séropositifs envers l'herpès virus bovin type 4 dans les plaines d'Accra au Ghana. Population bovine de la région : 61601 individus.

\begin{tabular}{|l|c|c|c|c|}
\hline \multicolumn{1}{|c|}{ Elevage } & Effectif & $\begin{array}{c}\text { Animaux } \\
\text { prélevés }\end{array}$ & $\begin{array}{c}\text { Animaux } \\
\text { positifs }\end{array}$ & $\begin{array}{c}\text { p. cent } \\
\text { d'animaux } \\
\text { positifs }\end{array}$ \\
\hline $\begin{array}{l}\text { Ranch } \\
\text { d'Aveyime }\end{array}$ & 2183 & 95 & 12 & 13 \\
\hline $\begin{array}{l}\text { Villages: } \\
\text { Fokwe }\end{array}$ & 4650 & 5 & 0 & \\
$\begin{array}{l}\text { Ntepaw } \\
\text { Kelorkpoe }\end{array}$ & 1030 & 9 & 1 & \\
$\begin{array}{l}\text { Autres } \\
\text { villages (5) }\end{array}$ & 500 & 61 & 11 & \\
Sous-total & 6680 & 81 & 12 & 15 \\
\hline Total & 8863 & 176 & 24 & 14 \\
\hline
\end{tabular}

cence indirecte envers le BHV-4 comme décrit précédemment (1). Une fluorescence spécifique à la dilution $1 / 100$ a été considérée comme positive ; une fluores cence non spécifique était encore observée à la dilution $1 / 10$ pour plusieurs sérums, suite à leur mauvais état de conservation. Quatroze pour cent des 176 sérums examinés sont positifs (tabl. I). On n'observe pas de différence (test de $\mathrm{Chi}^{2}, \mathrm{P}>0,05$ ) entre les sérums des animaux du ranch (13 p. 100 positifs) et ceux des villages (15 p. 100).

En Afrique, des souches appartenant probablement au groupe BHV-4 ont été isolées au Kenya, en Tanzanie et en Afrique du Sud sur des animaux présentant des lésions variées $(3,4,5)$. Une enquête sérologique plus récente au Zaiire a révélé que l'infection y était largement répandue (2) ; mais les sérums y ont été examinés à la dilution $1 / 20$, ce qui peut expliquer en partie la prévalence plus élevée (70 p. 100).

Au Ghana, les sérums étaient contaminés par des bactéries et n'ont pu être examinés par séroneutralisation du virus herpès bovin type 1 (virus de la rhinotrachéite infectieuse bovine), très répandu en Afrique subsaharienne (2) et agent causal d'une vaginite nécrotique des bovins (vulvovaginite infectieuse pustulaire).

L'infection par le BHV-4 est donc présente dans les plaines d'Accra, et même si le virus a joué un rôle pathogène douteux, ses relations avec le "syndrome épididymite - vaginite " doivent être gardées à l'esprit (5). Une enquête destinée à clarifier les relations entre l'infection par le BHV-4, les vaginites nécrotiques et la faible fertilité fréquemment observée dans la région, devrait donc être entreprise dans une phase ultérieure. 


\section{Communication}

MARCHOT (P.), THIRY (E.), JETTEUR (P.), LEROY (P.). Serological survey on bovine type-4 herpesvirus in cattle of the Accra Plains in Ghana. Revue Élev. Méd. vét. Pays trop., 1991, 44 (4) : 405406

Sera from cattle of the Accra Plains in Ghana were screened for bovine type-4 herpesvirus (BHV-4) antibodies by an indirect immunofluorescence test. Among the 176 screened serums, $14 \%$ were found positive at a $1 / 100$ dilution. Further studies are necessary for a better understanding of the relationships between $\mathrm{BHV}-4$ or some other agents and necrotic vaginitis associated with poor fertility observed in cattle in this area. Key words : Cattle Serological survey - Bovine type-4 herpesvirus - Vaginitis - Fertility Ghana.

\section{Bibliographie}

1. DUBUISSON (J.), THIRY (E.), THALASSO (F.), BUBLOT (M.), PASTORET (P.P.). Biological and biochemical comparison of bovid herpesvirus-4 strains. Vet. Microbiol., 1988, $16: 339349$.
2. EYANGA (E.), JETTEUR (P.), THIRY (E.), WELLEMANS (G.), DUBUISSON (J.), VAN OPDENBOSCH (E.), MAKUMBU (S.), PASTORET (P.P.). Recherche des anticorps dirigés contre les BHV-1, BHV-2, BIIV-4, le virus BVD-MD, les adénovirus A et $B$, le rotavirus et le coronavirus bovins chez des bovins de l'Ouest du Zaïre : résultats complémentaires. Revue Élev. Méd. vét. Pays trop., 1989, 42 (2) : 155-161.

3. KAMINJOLO (J.S.), MUGERA (G.M.), ROSTED (A.F.). Isolation of a herpes-type virus from some tumours of bovine origin. Zentbl. VetMed. B., $1972,19: 626-632$.

4. RWEYEMAMU (M.M.), LORETU (K.). Isolation of « non-syncytia forming » herpesviruses from cattle in Tanzania. J. Comp. Pathol., 1973, 83 (3) : 377-386

5. THEODORIDIS (A.). Preliminary characterization of viruses isolated from cases of epididymitis and vaginitis in cattle. Ondersterpoort I. Vet. Res., 1978, 45 (3) : 187-195.

6. THIRY (E.), BUBLOT (M.), DUBUISSON (J.), PASTORET (P.P.). Bovine herpesvirus 4 (BHV-4) infections of cattle. In : WITTMANN (G.). Ed. Herpesvirus diseases of cattle, horses and pigs. Developments in veterinary virology. Boston, Kluwer Academic Publishers, 1989, P. 96-115. 